\title{
The current screening programme for congenital transmission of Chagas disease in Catalonia, Spain
}

\author{
L Basile (chagas@gencat.cat) ${ }^{1}$, I Oliveira ${ }^{2}$, P Ciruela ${ }^{1}$, A Plasencia ${ }^{1}$, working group for developing the Catalonian Screening \\ Programme for congenital transmission of Chagas disease ${ }^{3}$ \\ 1. General Directorate of Public Health, Generalitat de Catalunya, Barcelona, Spain \\ 2. Barcelona Centre for International Health Research (CRESIB), University of Barcelona, Barcelona, Spain \\ 3. The members of the group are listed at the end of the article
}

Basile L, Oliveira I, Ciruela P, Plasencia A, working group for developing the Catalonian Screening Programme for congenital transmission of Chagas disease. The current screening programme for congenital transmission of Chagas disease in Catalonia, Spain.

Spain. Euro Surveill. 2011;16(38):pii=19972. Available online: http://www.eurosurveillance.org/ViewArticle.aspx?Articleld=19972.

Article published on 22 September 2011

Due to considerable numbers of migrants from Chagas disease-endemic countries living in Catalonia, the Catalonian Health Department has recently implemented a screening programme for preventing congenital transmission, targeting Latin American pregnant women who attend antenatal consultations. Diagnosis of Trypanosoma cruzi infection in women is based on two positive serological tests. Screening of newborns from mothers with positive serology is based on a parasitological test during the first 48 hours of life and/or conventional serological analysis at the age of nine months. If either of these tests is positive, treatment with benznidazole is started following the World Health Organization's recommendations. The epidemiological surveillance of the programme is based on the Microbiological Reporting System of Catalonia, a well established network of laboratories. Once a positive case is reported, the responsible physician is asked to complete a structured epidemiological questionnaire. Clinical and demographic data are registered in the Voluntary Case Registry of Chagas Disease, a database administered by the Catalonian Health Department. It is expected that this programme will improve the understanding of the real burden of Chagas disease in the region. Furthermore, this initiative could encourage the implementation of similar programmes in other regions of Spain and even in other European countries.

\section{Introduction}

Due to migration flows the traditional epidemiological pattern of Chagas disease has dramatically changed during the past decades [1]. Previously defined as a mainly rural vector-borne disease confined to South America [2], Chagas disease is nowadays diagnosed all over the world wherever there are Latin American migrants [3]. With a view to eliminating the transmission of Chagas disease in non-endemic countries, the World Health Organization (WHO) recommends strengthening national and regional capacities in order to prevent and control congenital transmission, and improving case management of congenital and noncongenital infections, including strategies for case finding, diagnosis and treatment at different healthcare levels $[4,5]$.

Unlike vector and oral transmission of the causative pathogen Trypanosoma cruzi, which is only possible in endemic areas, infection through blood and organ transplantation or vertical transmission of the parasite can occur in any country [6]. During the past decade some non-endemic countries, among others France, Spain and the United Kingdom, have established legal requirements to ensure the safety of blood supply and organ transplantation by monitoring them for Chagas disease $[7,8]$. However, systematic screening for $T$. cruzi among pregnant Latin American women in non-endemic countries is still uncommon.

To date only a few cases of congenital transmission in non-endemic countries have been published, the majority, seven of ten, from Spain [9]. The remaining three cases were reported in Switzerland (two cases) [10] and in Sweden (one case) [11]. These few documented cases do probably not reflect the true situation but rather reflect a lack of screening programmes and surveillance systems following $T$. cruzi-positive pregnant women and their children.

The clinical characteristics of congenital T. cruzi infection are heterogeneous, ranging from asymptomatic (60-90\% of infected newborns) [12-14] or oligosymptomatic infants to severe cases with meningoencephalitis, myocarditis or respiratory distress syndrome (RDS) $[13,15]$. Whilst effectiveness of Chagas disease treatment in women of reproductive age, aimed to prevent or reduce the likelihood of vertical transmission, remains controversial [16], treatment of infected children during the first year of life ensures therapeutic success in almost $100 \%$ of cases [17]. This highlights the importance of routinely testing newborns from T. cruzi-infected women. 
The need for early detection and treatment of congenitally transmitted cases prompted the Catalonian Health Department to implement a systematic screening programme for Chagas disease among Latin American pregnant women and their children [18]. In this paper we describe this screening programme that was developed thanks to the collaboration between different Catalonian experts on Chagas disease and the WHO Department of Control of Neglected Tropical Diseases. It was implemented in Catalonia from January 2010.

The programme encompasses serological screening of Latin American pregnant women attending antenatal consultation, screening and treatment of their newborns, and an epidemiological surveillance system.

\section{Screening strategy}

Screening of pregnant women

The main target population of the programme is Latin American pregnant women attending antenatal

\section{FIGURE 1}

Serological screening of pregnant Latin American women for Chagas disease, Catalonia

Latin American pregnant woman

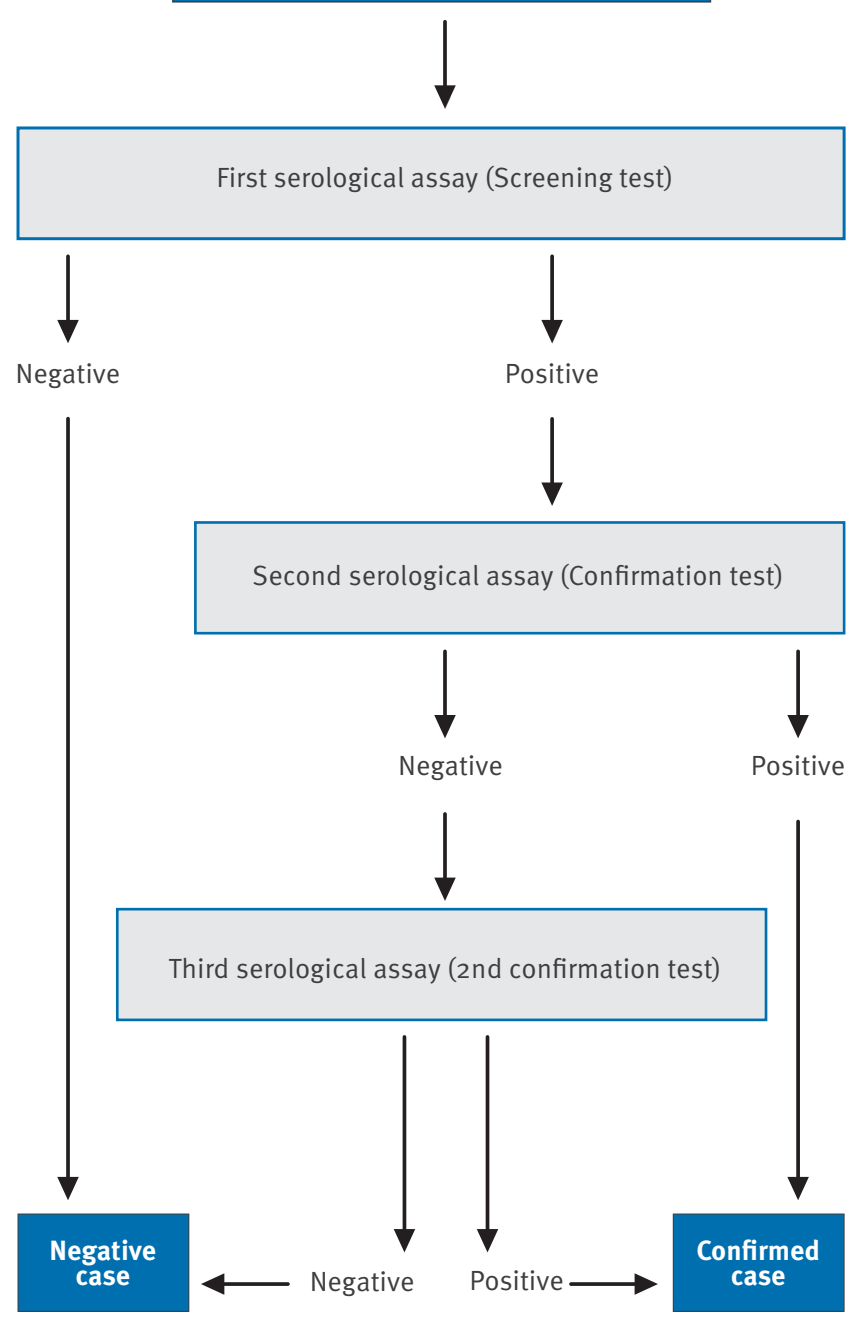

consultation in Catalonia. The health system in Spain is universal and free of charge, thus it is unlikely that pregnant migrants, even if undocumented, will not attend the antenatal consultations. Screening for Chagas disease is offered during the first trimester of pregnancy (or whenever the women sought healthcare in the case of uncontrolled pregnancies) to all Latin American women from endemic countries (Argentina, Belize, Bolivia, Brazil, Chile, Colombia, Costa Rica, Ecuador, El Salvador, Guatemala, Guyana, French Guyana, Honduras, Mexico, Nicaragua, Panama, Paraguay, Peru, Surinam, Uruguay, Venezuela), Spanish women born to Latin American mothers (second generation) and Spanish female travellers who have been living in endemic areas for more than one month [18].

The laboratory diagnosis during the chronic phase of Chagas disease is based on two serological tests. Commercially available assays use either lysates of the epimastigote form of the parasite grown in liquid culture or recombinant antigens [19]. Given the lack of a widely accepted standard for serological diagnosis of chronic T. cruzi infected patients, the Pan American Health Organization (PAHO) recommends to perform the diagnosis with two serological assays performed in parallel [20]. Within these limits, the 40 laboratories participating in the programme use their own testing algorithm for the screening pregnant women (Figure 1). The different serological assays used in the region are summarised in the Table. If the two chosen serological techniques give conflicting results, one additional test is performed in a reference laboratory [18].

When the diagnosis of T. cruzi infection is established, the women are referred to medical consultation. Specific treatment for Chagas disease in these women is only offered once they have stopped breast-feeding.

\section{TABLE}

Assays available in Catalonian laboratories for the diagnosis of chronic Chagas disease

\begin{tabular}{|l|}
\hline Enzyme-linked immunosorbent assays (ELISA) \\
\hline Bioelisa Chagas (Biokit, Lliça d'Amunt, Barcelona, Spain) \\
\hline ELISA cruzi Chagas disease (BioMerieux, Marcy-L'Etoile, France) \\
\hline $\begin{array}{l}\text { Whole Cell Lysate Antigen ORTHO Trypanosoma cruzi ELISA Test } \\
\text { System (Johnson and Johnson, HighWycombe, United Kingdom) }\end{array}$ \\
\hline Chagas IFA IgG + IgM (Vircell, Granada, Spain) \\
\hline Architect Chagas (Abbott, Spain) \\
\hline Indirect immunofluorescence (IF) \\
\hline Chagas IFA IgG + Ig M (Vircell, Granada, Spain) \\
\hline Inmunofluor Chagas (Biocientifica S.A., Buenos Aires, Argentina) \\
\hline IFI Mardx Diagnostics inc. (Trinity Biotech, Ireland) \\
\hline Rapid tests \\
\hline OnSite Chagas AB (CTK, Biotech, Inc., San Diego, United States) \\
\hline Simple Stick Chagas (Operon S.A., Zaragoza, Spain) \\
\hline Others assays \\
\hline In house Western blot (WB) \\
\hline
\end{tabular}


Screening of newborns and their siblings

Diagnostic screening is provided for newborns born from serological positive mothers. Direct microscopic examination of the buffy coat of blood from heparinised microhaematocrit tubes or using the Strout technique were the standard parasitological tests used for diagnosis of congenital transmission in the Catalonian programme [18]. The screening for T. cruzi infection is preferably carried out within the first 48 hours of the newborn's life whether it has symptoms or not. If the microhaematocrit is positive, the newborn is considered infected and specific treatment is started. When screening is not performed early in life or if the parasitological test is negative in the first hours, the children continue normal follow-up until they are nine months old. At that age the children are tested with a conventional serological analysis to detect specific immunoglobulin G (IgG) (Figure 2). IgG maternal antibodies against $T$. cruzi disappear in non-infected infants older than eight months [21]. In the case of a positive parasitological test at birth or a positive serological result at nine months, treatment is carried out according to WHO recommendations [5]. The most widely used drug for treating congenital Chagas disease in Spain is benznidazole, although nifurtimox has a similar efficacy profile [22]. Screening and, if necessary, treatment for Chagas disease are also extended to the other children of $T$. cruzi-positive mothers.
Although some studies have suggested that PCR can be more sensitive than parasitological techniques for early detection of congenital infections [23], the PCR was not included in the programme [18] following WHO recommendations [5]. It seems reasonable to assume that standardisation of PCR techniques will lead to the inclusion of this tool in the future.

\section{Epidemiological surveillance system}

The epidemiological surveillance of Chagas disease for the screening programme is based on the Microbiological Reporting System of Catalonia (MRSC). This is a collaborative network of Catalonian laboratories that has been collecting information from different pathogens of public health importance since 1993. A total of 40 microbiology laboratories encompassing 47 hospitals and health centres throughout Catalonia participate in this system. These centres include the largest hospitals and represent more than $80 \%$ of hospital beds in the region (a list of the laboratories is available at: http://www.gencat.cat/salut/depsalut/html/ca/ dir2088/labs_notif_microb.pdf).

When a positive case of $T$. cruzi infection among pregnant women or their children are reported by laboratories to the MRSC, the Catalonian Health Department contacts the physician in charge of the patient and a structured epidemiological questionnaire is completed.

\section{FIGURE 2}

Serological screening for Chagas disease of Latin American newborns and their siblings, Catalonia

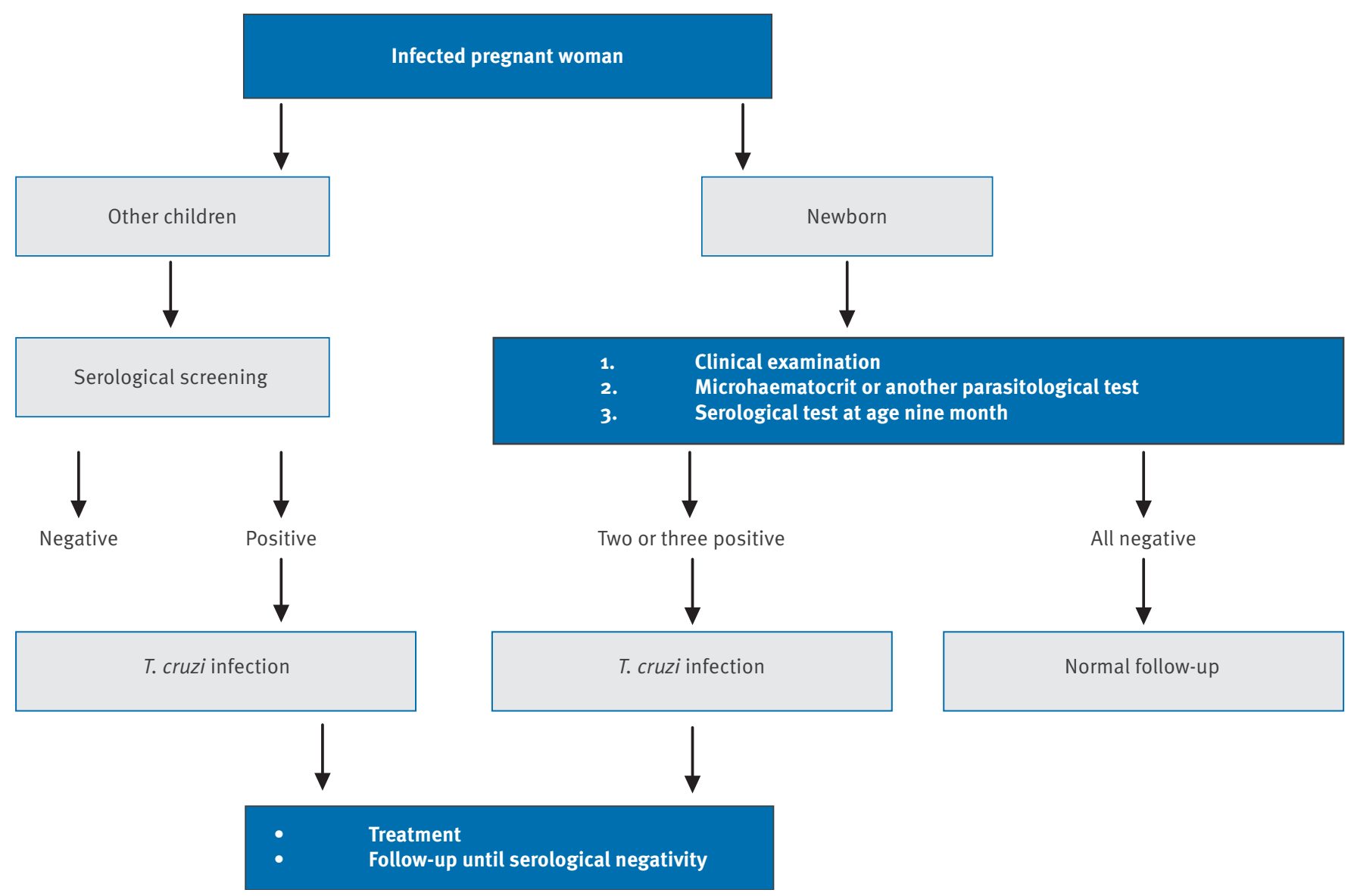


Clinical and demographic collected data is registered in the Voluntary Case Registry of Chagas Disease, a database administered by the Catalonian Health Department (Figure 3).

The main goals of this surveillance system are to assess the implementation of the protocol in the region and to periodically report the results to health providers and public health authorities.

\section{Discussion}

Different factors contributed to the decision of the implementation of this screening programme in Catalonia [18]. Firstly, due to migration flows, the Latin American migrant population in Spain has increased dramatically in the last 10 years, reaching just under two million migrants in 2010 [24]. Ecuador, Argentina and Bolivia were the predominant countries of origin, and represented almost $50 \%$ of all Latin American migrants living in the country [24]. Consequently, the estimated number of patients infected with Chagas disease was also high in Spain and vertical transmission of this disease a potential risk [25]. Applying the seroprevalence estimates published by the PAHO in

\section{FIGURE 3}

Surveillance system for the Chagas disease screening programme, Catalonia

\section{Confirmation of $T$. cruzi infection in pregnant woman}

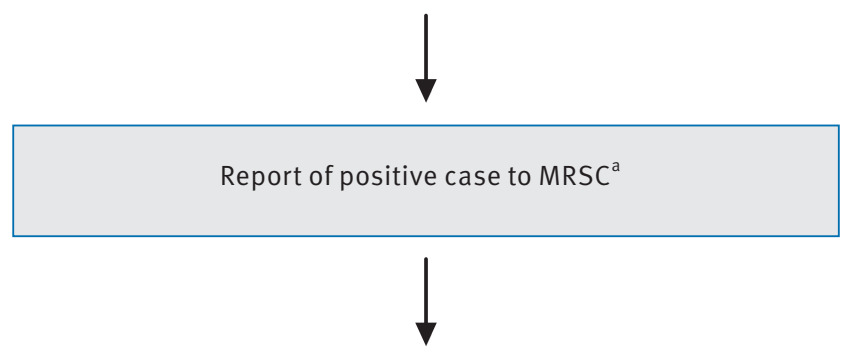

1. Contact physician in charge of the patient

2. Monitoring of newborn and others children

3. Delivery of epidemiological records for mother and positive children

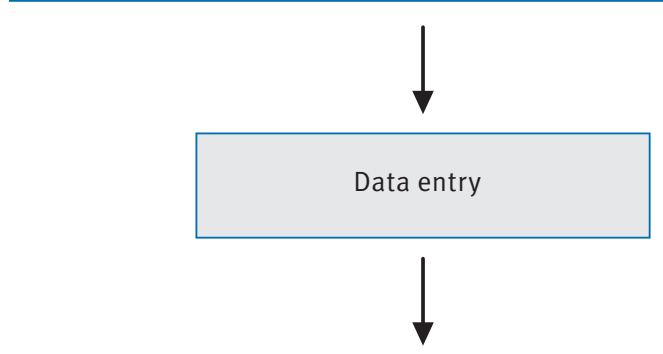

Voluntary Case Registry of Chagas disease in Catalonia

a Microbiological Reporting System of Catalonia
2006 it was estimated that between 39,985 and 65,258 T. cruzi-infected individuals were living in Spain in 2008 [5]. Taking into account that 35,525 children were born to Latin American women during that year, it was estimated that between 914 and 1,656 of these mothers were infected with $T$. cruzi. Assuming a transmission rate between $4.5 \%$ and $7.3 \%$, the expected number of infected newborns would range between 41 and 121 [5].

For Catalonia, it was estimated that between 10,000 and 20,000 T. cruzi-infected migrants were living in this region in 2010 [26]. The number of pregnancies in women from endemic countries during that year was of 6,795. Considering that between 203 and 387 women could be infected, the expected number of $T$. cruzi infected newborns within this region for 2010 could range between seven and 16 (personal communication: Maternal and Child Health Programme, Directorate of Public Health, Generalitat of Catalonia, September 2011).

Secondly, a study carried out in the main maternity wards in Barcelona between 2005 and 2007 documented that the potential risk for vertical transmission of Chagas disease in Catalonia was already a reality [27]. During these years 1,350 Latin American pregnant women from endemic countries were tested, and 46 were found to be positive for $T$. cruzi, with a general seroprevalence of Chagas disease of $3.4 \%(27,5 \%$ among Bolivian women). Three of the 41 children with follow-up in that survey were infected, giving a vertical transmission rate of $7.3 \%$ [27]. Two further cases of vertical transmission, not related to the above study, were also reported in the region in 2004 [28] and in 2006 [29].

Finally, a study assessing the economic impact of Chagas disease screening programmes among pregnant women in a non-endemic area such as Spain was carried out in Barcelona in 2009 [30]. Two decision models were evaluated; the option of screening the newborn and the mother versus not screening either of them [30]. In this study the screening of Latin American pregnant women and their infants was the more costeffective strategy compared with the option not to screen [30].While the therapeutic success in chronic infected adults with Chagas disease is poor, between $8 \%$ and $25 \%$ [31], treatment of infected children during the first year of life ensures therapeutic success in almost $100 \%$ of cases [17] and avoids all medical costs relative to a delayed symptomatic manifestation of the disease.

Currently, recognition of Chagas disease in Europe is low and there are no programmes for the prevention of vertical transmission implemented at national level in any European country. In Spain, a similar regional initiative has been implemented in the Valencian Community in 2009, although with the difference that an epidemiological surveillance system linked to the programme was not established [32]. 
During the implementation of the Catalonian screening programme, we noticed that the knowledge of healthcare providers about Chagas disease was limited, a situation that is similar in other non-endemic countries [33]. To solve this inadequacy, continued training and information brochures has been offered to all personnel involved in the diagnosis and care of patients with Chagas disease.

The main challenge in the implementation of this protocol has been the coordination between the different levels of the health system. It is essential to increase networking between primary healthcare providers and hospitals and to reinforce the communication with public health authorities. To achieve the goal of the elimination of Chagas disease transmission, the WHO aims to reinforce regional and national capacities and strengthen worldwide epidemiological surveillance systems [4]. In this sense, one of the strengths of this programme is the source of data. The MRSC is an already well established network for public health surveillance that encompasses the majority of diagnostic laboratories in Catalonia. This system provides robust and reliable information, decreasing the risk of information bias.

The main limitation of this surveillance system is that the MRSC does not cover all the laboratories within the region. To solve this problem, hospitals and laboratories not covered by the MRSC network are asked monthly to report $T$. cruzi-infected patients. Moreover, in the surveillance system only positive cases are collected, so for now it is difficult to calculate the programme coverage without the information on all screened cases. Regard this problem; other solutions are currently being explored.

\section{Conclusions}

Non-endemic countries should consider congenital T. cruzi infection as a public health problem. Estimation of the burden of Chagas disease among migrants from endemic countries is essential to develop preventive measures and the right tools for the management of this disease in destination countries.

A screening program for $T$. cruzi in Latin American pregnant women, such as the one currently in place in Catalonia, would improve the knowledge about the real burden of Chagas disease in a non-endemic setting. This protocol is only a small step towards the goal of controlling Chagas disease worldwide, but we hope it may encourage the implementation of similar programmes in other regions of Spain and even in other European countries.

\section{Acknowledgments}

We would like to thank all the microbiology laboratories that participate in the MRSC for their collaboration. We are also grateful to all health providers who work daily with Chagas disease in Catalonia and make the implementation of this protocol a reality.
Members of the working group for developing the Catalonian Screening Programme for congenital transmission of Chagas disease:

Catalonian Health Department, Barcelona, Spain: Admetlla M., Calvo E., Cardeñosa M., Carmona G., Costa D., De la Puente M., Escuriet R., Godoy P., Jané M., Jansa JM., Ollé C., Pueyo MJ., Quesada M.; Servei Català de la Salut, Barcelona, Spain: Cutillas S.; Drassanes Tropical Medicine and International Health Unit, Barcelona, Spain: Gomez i Prat J.; Barcelona Centre for International Health Research (CRESIB), Hospital Clinic Barcelona, Barcelona, Spain: Gascón J., Pinazo MJ., Vila J.; Hospital Clinic Barcelona, Barcelona, Spain: Coll O., Mas J., Pérez JM., Valls ME.; Faculty of Pharmacy, Universitat de Barcelona, Barcelona, Spain: Portús M.; Banc de Sang i Teixits, Servei Català de la Salut, Barcelona, Spain: Sauleda S.; SAP Laboratory, Catalonian Health Institute: Fernández A.; Hospital Germans Trias i Pujol, Barcelona, Spain: Rodrigo C.; Hospital Comarcal Alt Penedes, Barcelona, Spain: Delgado LI.; Hospital Joan XXIII, Tarragona, Spain: Soriano A.; Hospital Vall d'Hebrón, Barcelona, Spain: Molina I.; WHO Programme on Control of Chagas Disease, Geneve, Switzerland: Albajar-Viñas

\section{References}

1. Schmunis GA, Yadon ZE. Chagas disease: a Latin American health problem becoming a world health problem. Acta Trop 2010;115(1-2):14-21.

2. Gürtler RE, Segura EL, Cohen JE. Congenital transmission of Trypanosoma cruzi infection in Argentina. Emerg Infect Dis. 2003;9(1):29-32.

3. Muñoz J, Gómez i Prat J, Gállego M, Gimeno F, Treviño B, LópezChejade $P$, et al. Clinical profile of Trypanosoma cruzi infection in a non-endemic setting: immigration and Chagas disease in Barcelona (Spain). Acta Trop. 2009;111(1):51-5.

4. World Health Organization (WHO). Chagas disease: control and elimination. A62/17. 62nd World Health Assembly. Geneva, 1822 May 2009. Available from: http://apps.who.int/gb/ebwha/ pdf_files/A62/A62_17-en.pdf

5. World Health Organization (WHO). Control and prevention of Chagas disease in Europe. Report of a WHO Informal Consultation (jointly organized by WHO headquarters and the WHO Regional Office for Europe) Geneva, Switzerland, 17-18 December 2009. Geneva: WHO; 2010. Report No: WHO/HTM/NTD/IDM/2010.1 Available from: http://www. fac.org.ar/1/comites/chagas/Chagas_WHO_Technical\%20 Report_16_06_10.pdf

6. Piron M, Vergés M, Muñoz J, Casamitjana N, Sanz S, Maymó RM, et al. Seroprevalence of Trypanosoma cruzi infection in at-risk blood donors in Catalonia (Spain). Transfusion. 2008;48(9):1862-8.

7. Gascon J, Bern C, Pinazo MJ. Chagas disease in Spain, the United States and other non-endemic countries. Acta Trop. 2010;115(1-2):22-7.

8. Bern C, Montgomery SP, Katz L, Caglioti S, Stramer SL. Chagas disease and the US blood supply. Curr Opin Infect Dis. 2008;21(5):476-82.

9. Oliveira I, Torrico F, Muñoz J, Gascon J. Congenital transmission of Chagas disease: a clinical approach. Expert Rev Anti Infect Ther. 2010;8(8):945-56.

10. Jackson Y, Myers C, Diana A, Marti HP, Wolff H, Chappuis F, et al. Congenital transmission of Chagas disease in Latin American immigrants in Switzerland. Emerg Infect Dis. 2009;15(4):601-3.

11. Pehrson PO, Wahlgren M, Bengtsson E. Asymptomatic congenital Chagas' disease in a 5-year-old child. Scand J Infect Dis. 1981;13(4):307-8.

12. Altcheh J, Biancardi M, Lapeña A, Ballering G, Freilij H. [Congenital Chagas disease: experience in the Hospital de Ninos, Ricardo Gutierrez, Buenos Aires, Argentina]. Rev Soc Bras Med Trop. 2005;38 Suppl 2:41-5. Spanish.

13. Blanco SB, Segura EL, Cura EN, Chuit R, Tulián L, Flores I, et al. Congenital transmission of Trypanosoma cruzi: an operational outline for detecting and treating infected infants in northwestern Argentina. Trop Med Int Health. 2000;5(4):293-301.

14. Freilij H, Altcheh J. Congenital Chagas' disease: diagnostic and clinical aspects. Clin Infect Dis. 1995;21(3):551-5.

15. Torrico F, Alonso-Vega C, Suarez E, Rodriguez P, Torrico MC, Dramaix $M$, et al. Maternal Trypanosoma cruzi infection, 
pregnancy outcome, morbidity, and mortality of congenitally infected and non-infected newborns in Bolivia. Am J Trop Med Hyg. 2004;70(2):201-9.

16. Sosa-Estani S, Cura E, Velazquez E, Yampotis C, Segura EL. Etiological treatment of young women infected with Trypanosoma cruzi, and prevention of congenital transmission. Rev Soc Bras Med Trop. 2009;42(5):484-7.

17. Moya P, Basso B, Moretti E. [Congenital Chagas disease in Cordoba, Argentina: epidemiological, clinical, diagnostic, and therapeutic aspects. Experience of 30 years of follow up]. Rev Soc Bras Med Trop. 2005;38 Suppl 2:33-40. Spanish.

18. Autonomous Government of Catalonia. Protocol for screening and diagnosing Chagas disease in pregnant Latin American women and their newborns. Barcelona: Departament de Salut, Genaralitat de Catalunya; 2010. Available from: http://www. gencat.cat/salut/depsalut/html/en/dir3559/chagasprot_eng. pdf

19. Otani MM, Vinelli E, Kirchhoff LV, del Pozo A, Sands A, Vercauteren $\mathrm{G}$, et al. WHO evaluation of serologic assays for Chagas disease. Transfusion. 2009 Jun;49(6):1076-82.

20. Camargo ME, Segura EL, Kagan IG, Souza JM, Carvalheiro Jda R, Yanovsky JF, et al. Three years of collaboration on the standardization of Chagas' disease serodiagnosis in the Americas: an appraisal. Bull Pan Am Health Organ. 1986;20(3):233-44

21. Chippaux JP, Clavijo AN, Santalla JA, Postigo JR, Schneider D, Brutus L. Antibody drop in newborns congenitally infected by Trypanosoma cruzi treated with benznidazole. Trop Med Int Health. 2010;15(1):87-93.

22. Bern C, Montgomery SP, Herwaldt BL, Rassi A Jr., Marin-Neto JA, Dantas RO, et al. Evaluation and treatment of chagas disease in the United States: a systematic review. JAMA. 2007 14;298(18):2171-81.

23. Mora MC, Sanchez Negrette O, Marco D, Barrio A, Ciaccio M, Segura MA, et al. Early diagnosis of congenital Trypanosoma cruzi infection using PCR, hemoculture, and capillary concentration, as compared with delayed serology. J Parasitol. 2005;91(6):1468-73.

24. Instituto Nacional de Estadística (IDE). [National Statistics Institute]. Revisión del Padrón municipal 2010. Datos a nivel nacional, comunidad autónoma y provincia. [Municipal Register Review of 2010. Data at the national, autonomous community and province]. Accessed: 20 Feb 2011. Spanish. Available from: http://www.ine.es/jaxi/menu.do?type $=$ pcaxis \&file $=$ pcaxis \&pa th $=\% 2 \mathrm{Ft} 20 \% 2 \mathrm{Fe} 245 \% 2 \mathrm{Fpo} \% 2 \mathrm{~F} \% 2 \mathrm{Fa} 2010$

25. Guerri-Guttenberg RA, Grana DR, Ambrosio G, Milei J. Chagas cardiomyopathy: Europe is not spared! Eur Heart J. 2008;29(21):2587-91.

26. Instituto de estadística de Cataluña (IDESCAT).[Statistics institute of Catalonia]. Població estrangera per països. 2010 Catalunya . [Foreign population by country. Catalonia 2010]. Accessed: 1 Jul 2011. Spanish. Available from: http://www. idescat.cat/poblacioestrangera/?b=12

27. Muñoz J, Coll O, Juncosa T, Vergés M, del Pino M, Fumado V, et al. Prevalence and vertical transmission of Trypanosoma cruzi infection among pregnant Latin American women attending 2 maternity clinics in Barcelona, Spain. Clin Infect Dis. 2009 15;48(12):1736-40.

28. Muñoz J, Portús M, Corachan M, Fumadó V, Gascon J. Congenital Trypanosoma cruzi infection in a non-endemic area. Trans R Soc Trop Med Hyg. 2007;101(11):1161-2.

29. Riera C, Guarro A, Kassab HE, Jorba JM, Castro M, Angrill R, et al. Congenital transmission of Trypanosoma cruzi in Europe (Spain): a case report. Am J Trop Med Hyg. 2006;75(6):1078-81.

30. Sicuri E, Muñoz J, Pinazo MJ, Posada E, Sanchez J, Alonso PL, et al. Economic evaluation of Chagas disease screening of pregnant Latin American women and of their infants in a non endemic area.Acta Trop. 2011;118(2):110-7.

31. Gascón J, Albajar P, Cañas E, Flores M, Gómez i Prat J,Herrera $\mathrm{RN}$, et al. [Diagnosis, management and treatment of chronic Chagas' heart disease in areas where Trypanosoma cruzi infection is not endemic]. Enferm Infecc Microbiol Clin. 2008;26(2):99-106. Spanish.

32. Autonomous Government of Valencian Community. Enfermedad de Chagas importada. Protocolo de actuación en la Comunitat Valenciana. [Imported Chagas Disease. Protocol of actions in the Valencian Community]. Valencia: Conselleria de Sanitat, Generalitat Valenciana; 2009 Spanish. Available from: http:// biblioteca.sp.san.gva.es/biblioteca/publicaciones/MATERIAL/ PUBLICACIONES/INFAN MUJER/PERINATAL/MAMUAL ENF CHAGAS.PDF

33. Verani JR, Montgomery SP, Schulkin J, Anderson B, Jones JL. Survey of obstetrician-gynecologists in the United States about Chagas disease. Am J Trop Med Hyg. 2010;83(4):891- 